\title{
Chameleonic appearance of caseous calcification of the mitral valve - still a problem for its appropriate management
}

\author{
Caius Glad Streian ${ }^{1,2)}$, Ana LasCu ${ }^{3)}$, Raluca ŞOŞDean ${ }^{4,5)}$, Ciprian NiCuŞOR Dima ${ }^{1,2)}$, \\ FLORIN GROSU ${ }^{6}$ ), AdRIAN COSTACHE ${ }^{7)}$, ANDREI GHEORGHE MARIUS MOTOC ${ }^{8)}$
}

\author{
1) Department of Cardiovascular Surgery, Institute of Cardiovascular Diseases, Timişoara, Romania \\ 2) Discipline of Cardiovascular Surgery, Victor Babeş University of Medicine and Pharmacy, Timişoara, Romania \\ ${ }^{3)}$ Department of Functional Sciences, Victor Babeş University of Medicine and Pharmacy, Timişoara, Romania \\ 4) Department of Cardiology, Institute of Cardiovascular Diseases, Timişoara, Romania \\ 5) Discipline of Cardiology, Victor Babeş University of Medicine and Pharmacy, Timişoara, Romania \\ 6) Department of Histology, Victor Papilian Faculty of Medicine, Lucian Blaga University of Sibiu, Romania \\ 7) Department of Pathology, Carol Davila University of Medicine and Pharmacy, Bucharest, Romania \\ 8) Department of Anatomy and Embryology, Victor Babeş University of Medicine and Pharmacy Timişoara, Romania
}

\begin{abstract}
According to the research literature, the caseous calcification of the mitral annulus (CCMA) is a rare variant of the mitral annulus calcification (MAC) entity, described mostly in elderly women. The aim of this study was to present the case of a 53-year-old female patient with caseous calcification of the mitral valve annulus and posterior cusp, which was diagnosed as papillary fibroelastoma. An echo-dense and quasihomogeneous tumoral mass, measuring $1.6 / 1.4 \mathrm{~cm}$, at the level of the posterior mitral ring was detected by echocardiographic examination, as well as by cardiac magnetic resonance imaging (MRI). Histopathological analysis revealed fibrous connective tissue with myxoid areas, hyaline degeneration with unstructured necrosis and dystrophic calcifications, which was consisting with the operative findings of a "toothpaste tumor", or caseous calcification of the mitral valve. Differential diagnosis with other cardiac tumors, abscesses, thrombi or fibroelastomas is emphasized.
\end{abstract}

Keywords: caseous calcification, mitral annulus, mitral calcification, myxoid structure.

\section{Introduction}

There are several types of echo-dense masses that may be encountered on the native mitral valve ring and/or cusps. The most commonly described are myocardial abscesses, vegetations in infective endocarditis, thrombi and tumoral masses, which may include hemangioma of the mitral valve, intramural myxoma, leiomyosarcoma and/or fibroelastoma [1-4]. An estimated prevalence of approximately $0.6 \%$ of all cases of caseous mitral annulus calcification (MAC) can be sometimes mobile or produce mobile projections, which can embolize and be a source of stroke [5].

The caseous calcification of the mitral valve annulus is considered to be a rare entity representing caseous degeneration of the inner material in MAC and resembling as an echo-dense tumoral mass that typically affects the posterior annulus $[6,7]$. The cavity contents are composed of a calcium mixture, fatty acids, and cholesterol, with a "toothpaste-like" texture and it may present as an intracardiac mass or cavity [8]. It is usually benign but sometimes it may severely alter the mitral valve flow. It is important to distinguish between these masses in a correct manner using the available imaging techniques, as the correct diagnosis has important implications for the appropriate treatment [9].

\section{Aim}

We present hereby a case of caseous calcification of the mitral valve annulus and posterior cusp, which was diagnosed as papillary fibroelastoma, known to induce embolization [10].

\section{ㅁ Case presentation}

At the Department of Cardiology, Institute of Cardiovascular Diseases, affiliated to the Victor Babeş University of Medicine and Pharmacy, Timişoara, Romania, a 53-yearold female patient was evaluated for recently diagnosed grade II arterial hypertension.

She lacked any other known cardiac and/or extracardiac conditions. Her electrocardiography (ECG) and lab tests were normal. The echocardiographic examination showed normal sized heart cavities, with a normal left ventricular ejection fraction ( $60 \%$ by Simpson biplane method).

An unexpected echo-dense and quasi-homogenous tumoral mass, measuring $1.6 / 1.4 \mathrm{~cm}$, was detected at the level of the posterior mitral ring including the $\mathrm{P} 2$ segment of the posterior mitral leaflet, without any shadowing artifacts. The mass was round-shaped when examined in parasternal long axis and apical views (Figure 1A) and slightly oval shaped in parasternal short axis view, including

This is an open-access article distributed under the terms of a Creative Commons Attribution-NonCommercial-ShareAlike 4.0 International Public License, which permits unrestricted use, adaptation, distribution and reproduction in any medium, non-commercially, provided the new creations are licensed under identical terms as the original work and the original work is properly cited. 
most of the posterior mitral annulus and extending to the apical part of the P2 segment and apparently to the adjacent myocardium (Figure 1B). This resulted in a light mitral regurgitation. Infective endocarditis and mitral annulus abscess were excluded based on the patient's clinical status and medical history.

In order to better describe and distinguish the mass, a cardiac magnetic resonance imaging (MRI) was performed, which described a $138 \mathrm{~mm}^{3}$, well-defined, homogeneous tumor of the posterior mitral valve annulus and leaflet (mostly $\mathrm{P} 2$, extending to the medium-apical part) (Figure 2A), slightly hyperintense on T1-weighted sequences (Figure 2B) and slightly hypointense on T2-weighted sequences, with isointense signal during delayed postcontrast sequences/ without late gadolinium enhancement/with slight peripheral late gadolinium enhancement. This aspect excluded any highly vascular tumor like myxoma, hemangioma and leiomyosarcoma. The mass was interpreted as a possible papillary fibroelastoma, keeping in mind also a possible diagnosis of caseous necrosis of the mitral valve annulus. The patient was referred to the Department of Cardiovascular Surgery, Institute of Cardiovascular Diseases, affiliated to the Victor Babeş University of Medicine and Pharmacy, Timişoara, for surgical management. The intraoperative appearance was of a round, homogenous mass with a firm consistency (Figure 3). A white fibrocaseous tissue was eliminated while cutting the tumor, this macroscopic aspect suggesting a so-called "toothpaste tumor", or caseous calcification of the mitral valve (Figure 4). The mitral valve was replaced with a Sorin CarboMedics "Standard" $27 \mathrm{~mm}$ mechanical valve, with a good perioperatory outcome, without any complications.
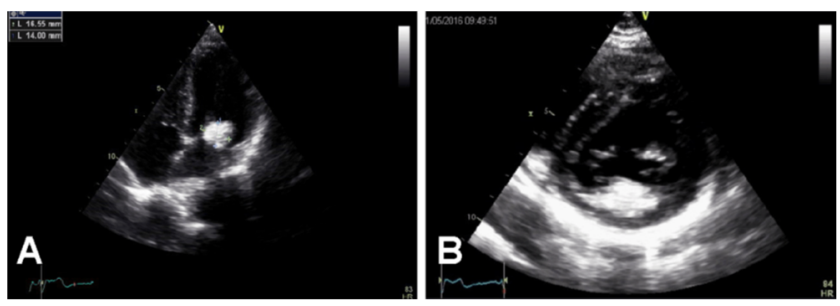

Figure 1 - Echocardiographic study: (A) Apical fourchamber view - echo-dense tumor mass at the level of the posterior mitral ring; (B) Parasternal short axis view.

Figure 2-MRI study: (A) Cine sequence, telediastolic four-chamber view - the tumor can be seen very well at the level of the mitral valve; (B) T1 sequence, mitral valve short axis view. MRI: Magnetic resonance imaging.
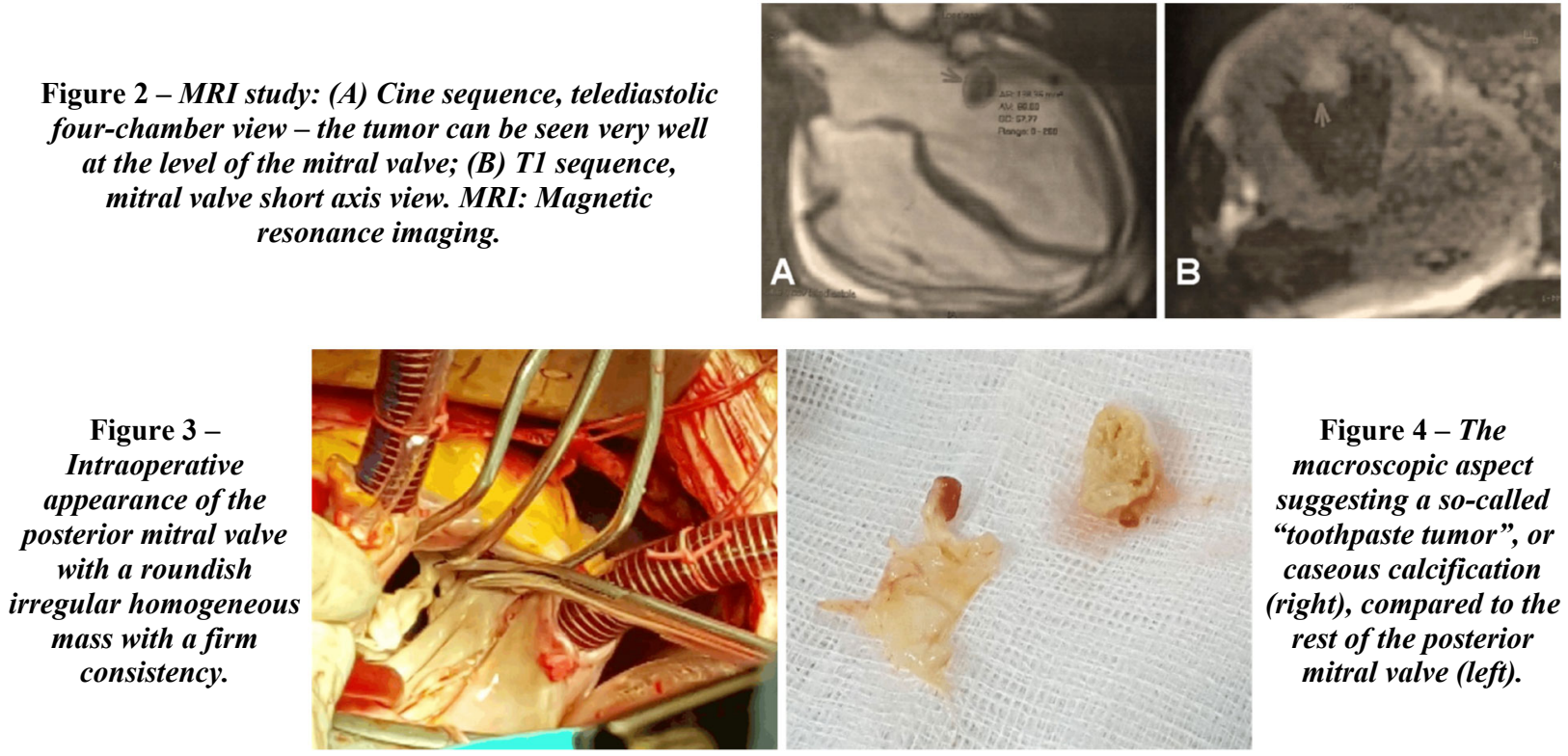

Tumor fragments were sent to the Laboratory of Pathological Anatomy for histopathological and immunohistochemical (IHC) study. After fixation in $10 \%$ neutral buffered formalin, paraffin embedding and microtome sectioning, tumor fragments were stained with HematoxylinEosin (HE) and Goldner-Szekely (GS) trichrome. The microscopic study showed the presence of fibrous connective tissue with myxoid areas (Figures 5 and 6), hyaline degeneration with unstructured necrosis, dystrophic calcifications, and diffuse chronic inflammatory infiltrate (Figures 7 and 8). Multinucleated macrophages were also detected, most probably due to an endogenous foreign body reaction (dystrophic calcifications). Some necrotic areas were surrounded by epithelioid histiocytes and/or by foamy macrophages.

For the IHC study, we used the following antibodies: anti-cluster of differentiation (CD) 3 (monoclonal mouse

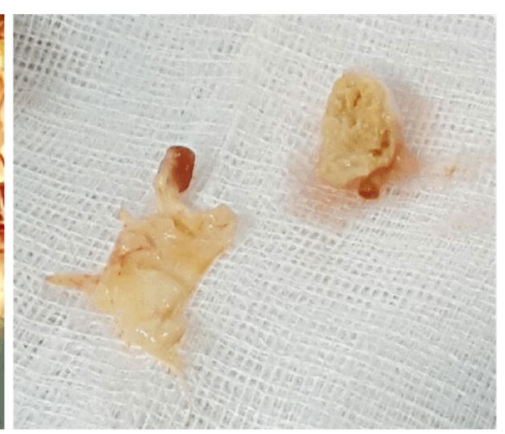

Figure 4-The macroscopic aspect suggesting a so-called “toothpaste tumor", or caseous calcification (right), compared to the rest of the posterior mitral valve (left).

anti-human CD3, clone F7.2.38, 1/25 dilution, Dako), antiCD20 (monoclonal mouse anti-human CD20cy, clone L26, 1/50 dilution, Dako), anti-CD68 (monoclonal mouse antihuman CD68, clone KP1, 1/100 dilution, Dako), antitryptase (monoclonal mouse anti-human mast cell tryptase, clone AA1, 1/500 dilution, Dako), anti-CD34 (monoclonal mouse anti-human CD34 class II, clone QBEnd-10, 1/50 dilution, Dako) and anti-alpha-smooth muscle actin ( $\alpha$-SMA) (monoclonal mouse anti-human SMA, clone 1A4, 1/100 dilution, Dako).

IHC examinations showed that the tumor consisted of connective tissue with inhomogeneous structure, areas of calcification of various sizes and a diffuse inflammatory infiltrate. Areas where inflammatory infiltrate was abundant were also frequently identified.

The inflammatory infiltrate was mainly composed of T-lymphocytes and macrophages, B-lymphocytes and mast 
cells being less identified (Figures 9-12). In some areas, numerous myofibroblasts have been identified, cells that are responsible for the synthesis of collagen fibers (Figure 13).

Tumor vascularization was generally reduced, the

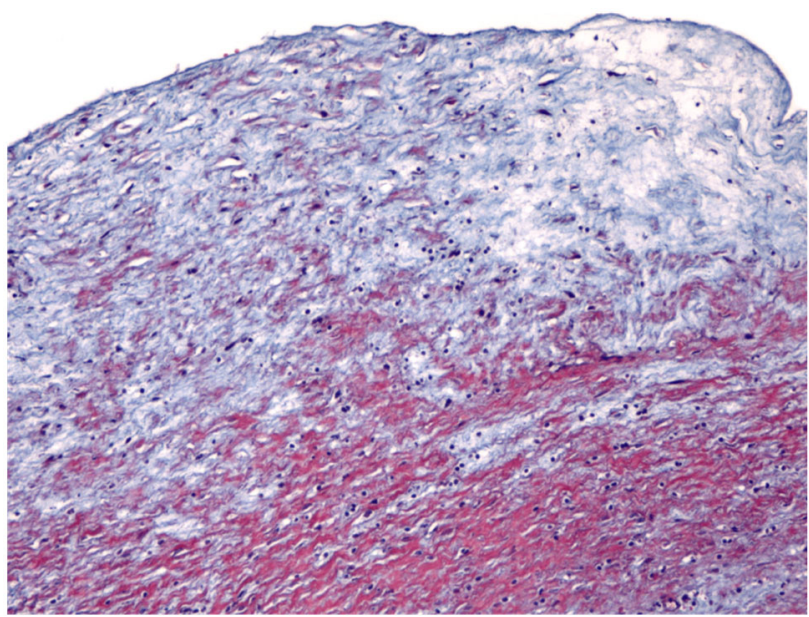

Figure 5 - Fibrosis and fibro-hyaline alteration of the mitral valve (GS trichrome staining, $\times 100)$.

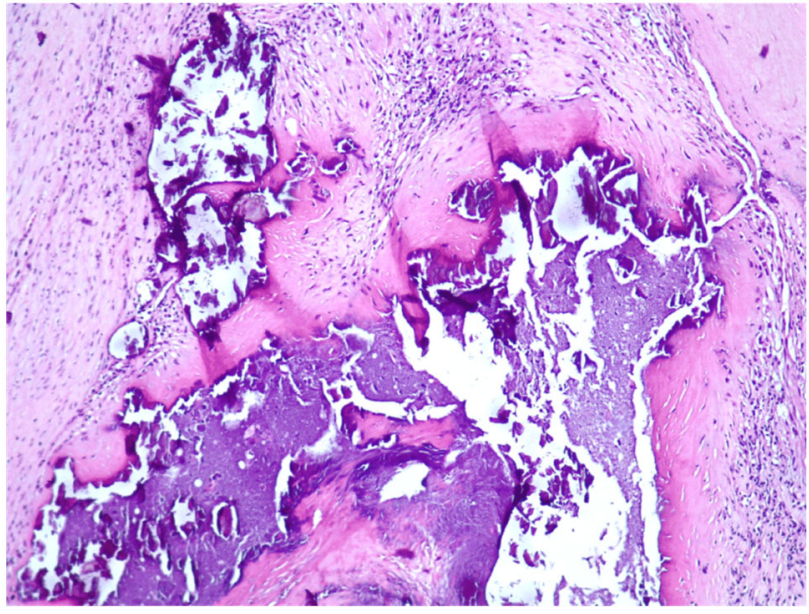

Figure 7 - Dystrophic calcification, fibrinoid necrosis (chronic ulceration) and chronic inflammatory infiltrate of the mitral valve (HE staining, $\times 40)$.

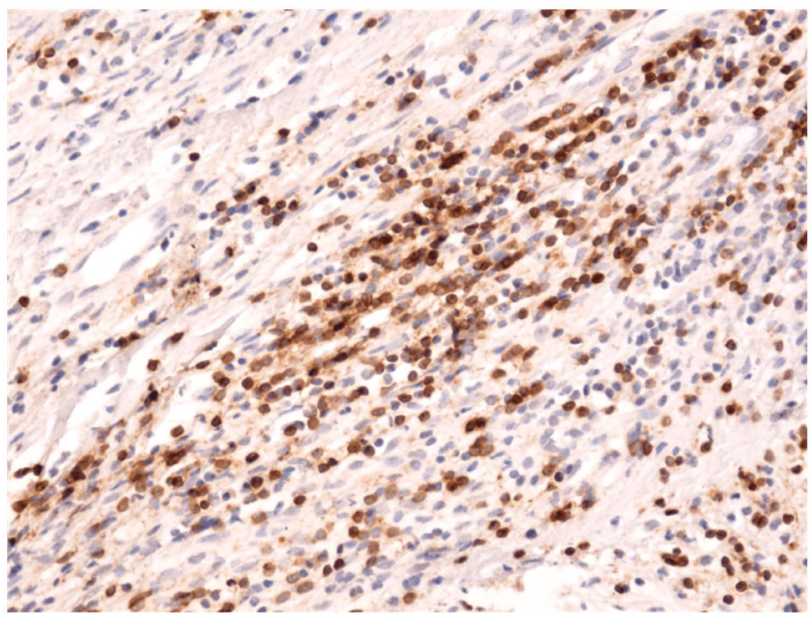

Figure 9 - Tumor area with an abundant inflammatory infiltrate consisting mainly of T-lymphocytes (Immunostaining with anti-CD3 antibody, $\times 200)$. CD3: Cluster of differentiation 3. blood vessels being few, except for the areas where the inflammatory infiltrate was abundant, areas where we found that the number of blood vessels was increased (Figure 14).

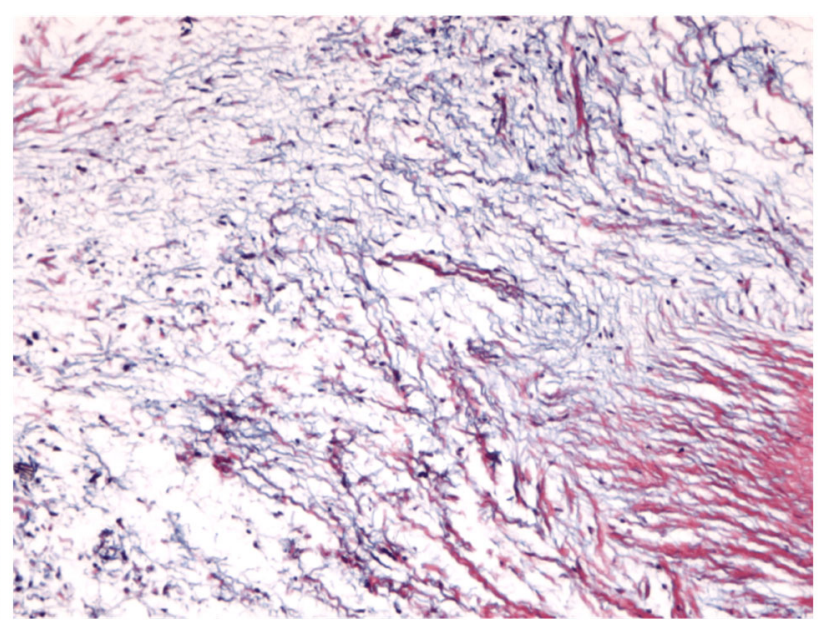

Figure 6 - Fibrous connective tissue with myxoid areas of the mitral valve (GS trichrome staining, $\times 100)$.

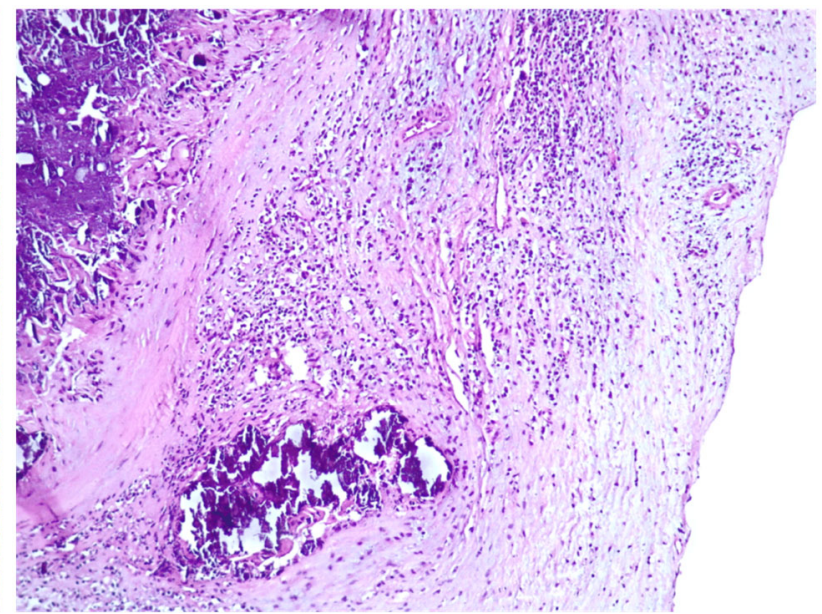

Figure 8 - Mitral valve with areas of dystrophic calcifications and abundant inflammatory infiltrate (HE staining, $\times 100$ ).

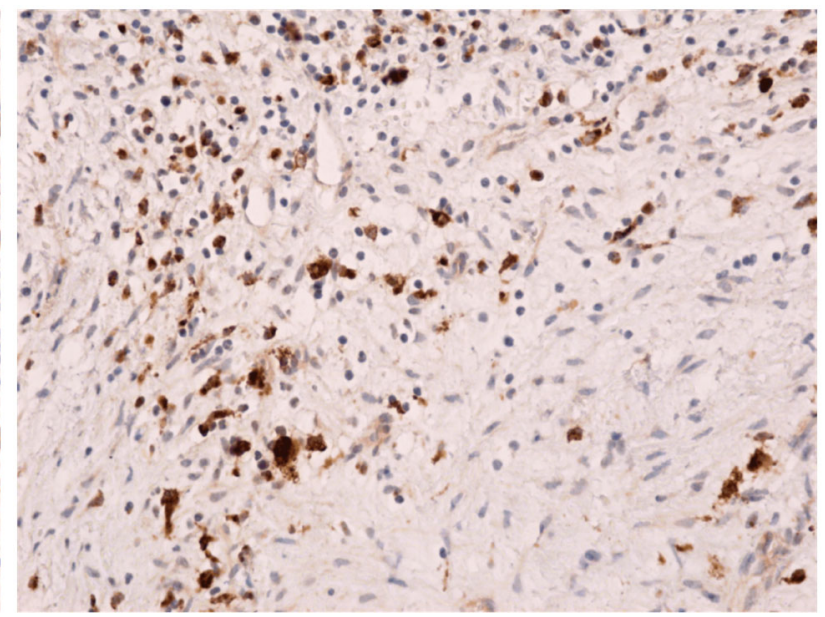

Figure 10 - Mitral valve area infiltrated with numerous macrophages (Immunostaining with anti-CD68 antibody, $\times 200)$. CD68: Cluster of differentiation 68. 


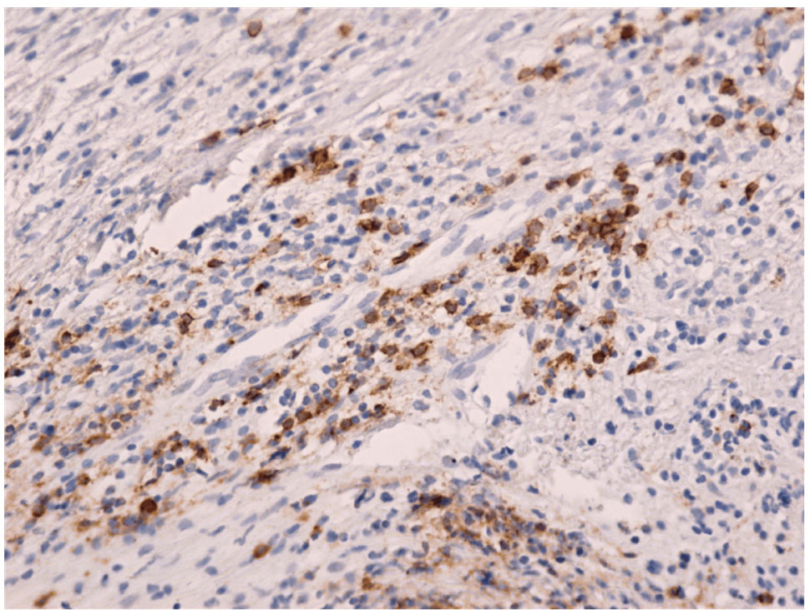

Figure 11 - Mitral valve area with an abundant inflammatory infiltrate, but with a small number of B-lymphocytes (Immunostaining with anti-CD20 antibody, ×200). CD20: Cluster of differentiation 20.

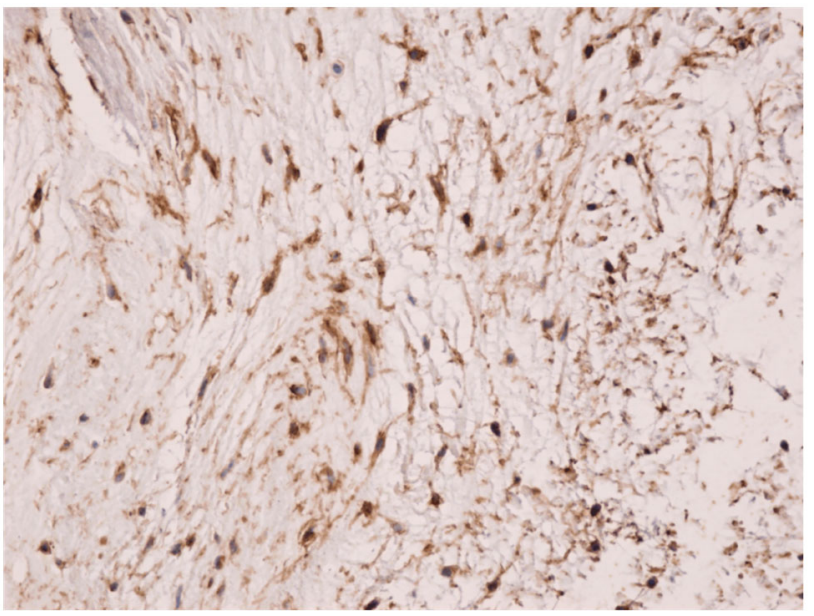

Figure 13 - Mitral valve area rich in myofibroblasts (Immunostaining with anti- $\alpha-S M A$ antibody, $\times 200$ ). $\alpha$ SMA: Alpha-smooth muscle actin.

\section{ㅁ Discussions}

Echocardiographic images of caseous calcification are often heterogenous due to calcium and lipid deposits. The masses show hyperechogenic and hypoechogenic areas. However, the caseous calcification appearance can imitate that of abscess, tumors, and cysts. And surgical treatment may not be needed when there is no obstruction. This entity is diagnosed on cardiac MRI, multi-modality imaging, especially non-contrast computed tomography (CT), and allows for the confident and prospective diagnosis [11, 12].

Microscopic examination in caseous calcification of the mitral annulus (CCMA) shows an amorphous acellular eosinophilic material with an inflammatory reaction based mostly on macrophages and lymphocytes surrounded and impregnated by necrotic and calcified tissue $[1,5]$, which is concordant with our findings. The timing of diagnosis and various amounts of calcified tissue, necrotic tissue, and inflammatory reaction, which may also vary in time, may be possible factors to induce the different imagistic aspect that made the diagnosis unclear. Cases that spontaneously resolved have already been published in the literature, demonstrating that this is a dynamic process [13].

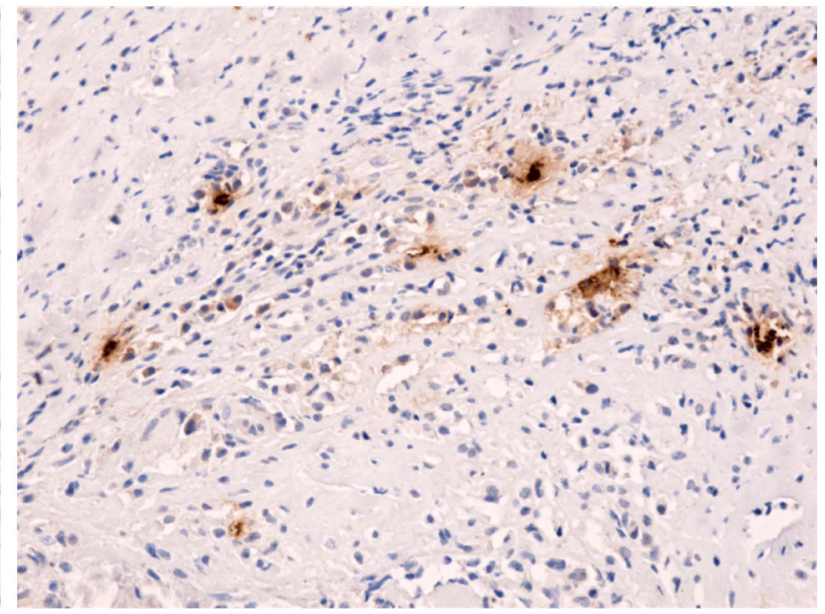

Figure 12 - Image of tumor tissue with few mast cells present in the inflammatory infiltrate (Immunostaining with anti-tryptase antibody, $\times 200$ ).

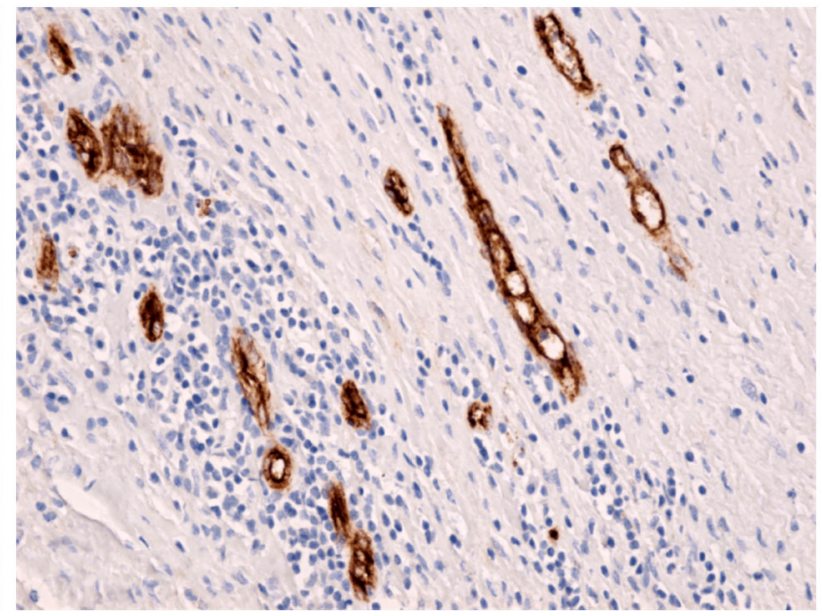

Figure 14 - Moderate inflammatory infiltrate, with numerous angiogenesis capillaries in an area of the mitral valve (Immunostaining with anti-CD34 antibody, $\times 200$ ). CD34: Cluster of differentiation 34.

CCMA is a rare variant of MAC entity, described mostly in elderly women. The mean age is 69 years old, with a history of hypertension, chronic kidney disease, especially with dialysis, calcium metabolism abnormalities, hypercholesterolemia, associated with a high calcium score, coronary artery disease (CAD) and aortic valve disease $[14,15]$.

In ambulatory patients with $\mathrm{CAD}$, mitral annular calcification was associated with inducible ischemia and subsequent cardiovascular events. MAC may indicate a high atherosclerotic burden and identifies patients at increased risk for adverse cardiovascular outcomes [16]. Given this profile, our 53-year-old patient, with a recently diagnosed hypertension is atypical, being the youngest reported with this disease, except for the renal failure patients. The exact mechanism of liquefaction necrosis is still unclear, but macrophages and an altered calcium metabolism seem to have a role [17].

Usually, this is an incidental finding. The echocardiographic aspect is of a large round or semilunar, inhomogeneous, echo-dense mass with central echolucency areas, without shadowing artifact [18]. Mid-basal involvement of the posterior mitral leaflet, besides the mitral annulus, 
was described with MAC but CCMA, with its tumoral aspect, is found in the posterior periannular area, rarely extending to the entire annulus, normally without mitral leaflet involvement [19]. Cases that involve the posterior and/or the anterior mitral valve leaflet are extremely rare $[19,20]$.

In hemodialysis patients, MAC is common and often extensive. In this case, calcium may be unevenly distributed among the annular segments. When present, the annular calcification reduces the leaflet angle opening and can produce valvular dysfunction [21].

In our case, the tumor-like mass involved also P2 segment of the posterior mitral leaflet, and the central echolucent areas were not evident. Usually, tumors lack this area of echolucency, except for the ones with necrotic areas [22]. Therefore, the diagnosis was not strikingly clear by using only echocardiography.

Whereas echocardiography was used to initially detect this mass and to assess its functional significance, the use of cardiac MRI was used to exclude other potential etiologies and to confirm the calcium presence. The conventional CT imaging further confirmed the calcified nature of the mass and most optimally demonstrated the transformation into caseous necrosis [23].

CT aspect is of a well-defined hyperdense mass, with peripheral calcification without contrast enhancement, but this investigation was not performed in our patient. MRI on the other hand is considered to be the method of choice in unclear cases. Here it is described as a welldefined mass, either hypointense in both T1- and T2weighted sequences $[24,25]$, or hyperintense in the central area with a hypointense rim in $\mathrm{T} 1$, discrete from the surrounding myocardium and as a mass with a hypodense central area with a high intensity ring in T2-weighted sequences [1]. In postcontrast studies, there is no contrast enhancement on first-pass sequences, but peripheral late gadolinium enhancement may be detected [2].

MRI aspect described in our case was not that obvious, the mass lacking any evident rims. The diagnosis of CCMA was still an option but valvular papillary fibroelastoma could not be excluded. This usually appears as uniform intermediate signal intensity mass similar to myocardium in T1- and T2-weighted sequences, normally lacking contrast enhancement, although cases with uniform late enhancement were reported [26]. Also, leaflet involvement, the age of the patient and the recently diagnosed hypertension as the only risk factor did not favor caseous calcification.

Although cases of CCMA embolization were reported in the literature $[1,4,10,27]$, due to surface thrombus formation, calcified material embolization and/or fistulization with necrotic material embolization, it is considered to be a benign entity and conservative treatment is usually recommended $[28,29]$. Surgical management is recommended in cases with significantly impaired valve function (severe stenosis and/or regurgitation), in cases with evidence of systemic embolism and in doubtful cases, when the diagnosis is not clear [1, 18]. Severe MAC makes valve surgery more difficult. The surgery risks and benefits must be carefully assessed in patients with significant MAC, as increased surgical mortality has been observed in these patients [30].

For the patients with documented calcified emboli or repeated thromboembolism despite anticoagulation, the valve replacement may be considered [31]. The associ- ation between MAC and incident atrial fibrillation may be partially explained by the left atrial enlargement [32].

The mitral annular calcification is an increasing problem in elderly people, causing both mitral stenosis and regurgitation, which are difficult to treat. There is a little experience with the use of transcatheter valves by either a catheter-based approach or as a hybrid technique [33]. The eighth edition of the American College of Chest Physicians Guidelines recommends the antithrombotic therapy with Aspirin (50-100 mg/day) [34]. These Guidelines also state that the Warfarin therapy (target international normalized ratio, 2.5; range, 2-3) may be considered under certain circumstances for long-term stroke prevention [35]. Papillary fibroelastoma, the alternate diagnosis in our case, has a high risk of embolization, and surgical treatment is usually recommended [36]. This is the reason why surgical management was preferred in our case.

\section{ㅁ Conclusions}

The caseous calcification of the mitral valve may also be encountered in younger patients lacking an association of multiple significant risk factors. It may sometimes have a less typical appearance, which makes it difficult to differentiate it from tumoral masses. Publishing these less typical cases is worthwhile in order to improve the entity's diagnosis.

\section{Conflict of interests}

The authors declare that they have no conflict of interests regarding the publication of this paper.

\section{References}

[1] Elgendy IY, Conti CR. Caseous calcification of the mitral annulus: a review. Clin Cardiol, 2013, 36(10):E27-E31. https:// doi.org/10.1002/clc.22199 PMID: 24038099 PMCID: PMC 6649616

[2] Balci S, Akkaya S, Ardali S, Hazirolan T. Caseous necrosis of mitral annulus. Case Rep Radiol, 2015, 2015:561329. https:// doi.org/10.1155/2015/561329 PMID: 26355421 PMCID: PMC 4556081

[3] García-lbarrondo N, Lang RM. Calcificación caseosa del anillo mitral, un raro hallazgo ecocardiográfico [Caseous calcification of the mitral annulus, a rare echocardiographic finding]. Rev Esp Cardiol, 2011, 64(9):828-831. https://doi.org/10.1016/j. recesp.2010.12.009 PMID: 21601976

[4] Fiore A, Grandmougin D, Maureira JP, Elfarra M, Folliguet T, Villemot JP. Caseous calcification of the mitral annulus: a neglected lesion mimicking intracardiac mass. Heart Lung Vessel, 2014, 6(2):128-129. PMID: 25024996 PMCID: PMC 4095841

[5] Deluca G, Correale M, leva R, Del Salvatore B, Gramenzi S, Di Biase M. The incidence and clinical course of caseous calcification of the mitral annulus: a prospective echocardiographic study. J Am Soc Echocardiogr, 2008, 21(7):828-833. https://doi.org/10.1016/j.echo.2007.12.004 PMID: 18222637

[6] Alkadhi H, Leschka S, Prêtre R, Perren A, Marincek B, Wildermuth $\mathrm{S}$. Caseous calcification of the mitral annulus. J Thorac Cardiovasc Surg, 2005, 129(6):1438-1440. https:// doi.org/10.1016/j.jtcvs.2004.11.051 PMID: 15942592

[7] Pala AA, Iner H, Ercisli MA. Approach to an unusual cardiac mass: mitral annulus caseoma. Braz J Cardiovasc Surg, 2020, 35(1):120-122. https://doi.org/10.21470/1678-9741-2018-0361 PMID: 31364345 PMCID: PMC7089747

[8] Harpaz D, Auerbach I, Vered Z, Motro M, Tobar A, Rosenblatt S. Caseous calcification of the mitral annulus: a neglected, unrecognized diagnosis. J Am Soc Echocardiogr, 2001, 14(8): 825-831. https://doi.org/10.1067/mje.2001.111877 PMID: 11490332

[9] Chahal M, Temesy-Armos P, Stewart WJ. Big MAC: caseous calcification of the mitral annulus referred for possible cardiac 
tumor. Echocardiography, 2011, 28(4):E76-E78. https://doi org/10.1111/j.1540-8175.2010.01321.x PMID: 21392087

[10] Findlay SG, Child NM, Muir DF. Caseous intracardiac calcification: a diagnostic enigma. Case Rep Cardiol, 2019, 2019 : 6707690. https://doi.org/10.1155/2019/6707690 PMID: 31110822 PMCID: PMC6487139

[11] Możeńska O, Sypuła S, Celińska-Spoder M, Walecki J, Kosior DA. Mitral annulus caseous calcification mimicking cardiac mass in asymptomatic patient - multimodality imaging approach to incidental echocardiographic finding. Pol J Radiol, 2014, 79:88-90. https://doi.org/10.12659/PJR.889830 PMID: 24791181 PMCID: PMC4005861

[12] Pradella S, Verna S, Addeo G, Oddo A, Miele V. Caseous calcification of the mitral annulus. J Radiol Case Rep, 2019 13(1):1-10. https://doi.org/10.3941/jrcr.v13i1.3554 PMID: 31565162 PMCID: PMC6743638

[13] Gramenzi S, Mazzola AA, Tagliaferri B, Protasoni G, Brusoni D, d'Aloya G, Brusoni B. Caseous calcification of the mitral annulus: unusual case of spontaneous resolution. Echocardiography, 2005, 22(6):510-513. https://doi.org/10.1111/j.15408175.2005.04056.x PMID: 15966936

[14] Al-Absi Al, Wall BM, Aslam N, Mangold TA, Lamar KD, Wan JY, D'Cruz IA. Predictors of mortality in end-stage renal disease patients with mitral annulus calcification. Am J Med Sci, 2006, 331(3):124-130. https://doi.org/10.1097/00000441-20 0603000-00003 PMID: 16538072

[15] Fox CS, Vasan RS, Parise H, Levy D, O'Donnell CJ, D’Agostino RB, Benjamin EJ; Framingham Heart Study. Mitral annular calcification predicts cardiovascular morbidity and mortality: the Framingham Heart Study. Circulation, 2003 107(11):1492-1496. https://doi.org/10.1161/01.cir.00000581 68.26163.bc PMID: 12654605

[16] Holtz JE, Upadhyaya DS, Cohen BE, Na B, Schiller NB, Whooley MA. Mitral annular calcium, inducible myocardial ischemia, and cardiovascular events in outpatients with coronary heart disease (from the Heart and Soul Study). Am J Cardiol, 2012, 109(8):1092-1096. https://doi.org/10.1016/j.amjcard.2011. 11.043 PMID: 22245404

[17] Arora H, Madan P, Simpson L, Stainback RF. Caseous calcification of the mitral annulus. Tex Heart Inst J, 2008, 35(2):211-213. PMID: 18612497 PMCID: PMC2435443

[18] Hamdi I, Chourabi C, Arous Y, Ghommidh M, Houissa K Haggui A, Hajlaoui N, Lahidheb D, Ben Abdallah N, Fehri W, Haouala $\mathrm{H}$. Multimodality imaging assessment of a caseous calcification of the mitral valve annulus. J Saudi Heart Assoc, 2018, 30(1):55-58. https://doi.org/10.1016/j.jsha.2017.04.007 PMID: 29296066 PMCID: PMC5744027

[19] Wynn GJ, Ruthven S, Fabri BM, Chenzbraun A. Caseous calcification of the anterior mitral leaflet: an unusual presentation of a rare pathology - role of 3D TEE. Eur Heart J Cardiovasc Imaging, 2012, 13(7):624. https://doi.org/10.1093/ ehjci/jes018 PMID: 22291428

[20] Khoshbin E, Brooks NH, Patrick M, Hooper TL. Restoration of mitral valve competence with the MitroFix device in a case of extensive caseous calcification of the posterior leaflet. Eur $\mathrm{J}$ Cardiothorac Surg, 2011, 40(6):1541. https://doi.org/10.1016/ j.ejcts.2010.12.031 PMID: 21345694

[21] Movva R, Murthy K, Romero-Corral A, Seetha Rammohan HR, Fumo P, Pressman GS. Calcification of the mitral valve and annulus: systematic evaluation of effects on valve anatomy and function. J Am Soc Echocardiogr, 2013, 26(10):1135-1142. https://doi.org/10.1016/j.echo.2013.06.014 PMID: 23876995

[22] Di Bella G, Carerj S, Andò G, Minutoli F, Celona A, Coglitore S, Arrigo F. Cardiac imaging in the evaluation of mitral annulus caseous calcification. Int J Cardiol, 2006, 113(1):E30-E31. https://doi.org/10.1016/j.ijcard.2006.07.084 PMID: 17052772

[23] Blankstein R, Durst R, Picard MH, Cury RC. Progression of mitral annulus calcification to caseous necrosis of the mitral valve: complementary role of multi-modality imaging. Eur Heart J, 2009, 30(3):304. https://doi.org/10.1093/eurheartj/ehn411 PMID: 18784062

[24] Shah BN, Babu-Narayan S, Li W, Rubens M, Wong T. Severe mitral annular calcification: insights from multimodality imaging. Tex Heart Inst J, 2014, 41(2):245-247. https://doi.org/10.145 03/THIJ-12-3028 PMID: 24808796 PMCID: PMC4004498

[25] Gulati A, Chan C, Duncan A, Raza S, Kilner PJ, Pepper J. Multimodality cardiac imaging in the evaluation of mitral annular caseous calcification. Circulation, 2011, 123(1):e1-e2. https://doi. org/10.1161/CIRCULATIONAHA.110.954313 PMID: 21200011

[26] Hoey ETD, Shahid M, Ganeshan A, Baijal S, Simpson H, Watkin RW. MRI assessment of cardiac tumours: part 1, multiparametric imaging protocols and spectrum of appearances of histologically benign lesions. Quant Imaging Med Surg, 2014, 4(6):478-488. https://doi.org/10.3978/j.issn.2223-4292. 2014.11.23 PMID: 25525581 PMCID: PMC4256239

[27] Kizer JR, Wiebers DO, Whisnant JP, Galloway JM, Welty TK, Lee ET, Best LG, Resnick HE, Roman MJ, Devereux RB. Mitral annular calcification, aortic valve sclerosis, and incident stroke in adults free of clinical cardiovascular disease: the Strong Heart Study. Stroke, 2005, 36(12):2533-2537. https:// doi.org/10.1161/01.STR.0000190005.09442.ad PMID: 16254219

[28] Chevalier B, Reant P, Laffite S, Barandon L. Spontaneous fistulization of a caseous calcification of the mitral annulus: an exceptional cause of stroke. Eur J Cardiothorac Surg, 2011, 39(6):e184-e185. https://doi.org/10.1016/j.ejcts.2011.01.038 PMID: 21376613

[29] Durāo D, Pitta Mda L, Alves M, Cabanelas N, Peres M, Aranha J, Monteiro I, Martins VP, Francisco A, Leal M, Loureiro J, da Silva GF. Myocardial infarction as the first probable manifestation of caseous calcification of the mitral annulus. Rev Port Cardiol, 2009, 28(11):1271-1275. PMID: 20222349

[30] Davidson MJ, Cohn LH. Surgical treatment of caseous mitral valve annulus calcification. J Thorac Cardiovasc Surg, 2006, 131(3):738-739. https://doi.org/10.1016/j.jtcvs.2005.11.025 PMID: 16515935

[31] Carpentier AF, Pellerin M, Fuzellier JF, Relland JY. Extensive calcification of the mitral valve anulus: pathology and surgical management. J Thorac Cardiovasc Surg, 1996, 111(4):718729; discussion 729-730. https://doi.org/10.1016/s0022-5223 (96)70332-x PMID: 8614132

[32] Fox CS, Parise H, Vasan RS, Levy D, O'Donnell CJ, D’Agostino RB, Plehn JF, Benjamin EJ. Mitral annular calcification is a predictor for incident atrial fibrillation. Atherosclerosis, 2004, 173(2):291-294. https://doi.org/10.1016/j. atherosclerosis.2003.12.018 PMID: 15064104

[33] Nishimura RA, Vahanian A, Eleid MF, Mack MJ. Mitral valve disease - current management and future challenges. Lancet, 2016, 387(10025):1324-1334. https://doi.org/10.1016/S0140 -6736(16)00558-4 PMID: 27025438

[34] Salem DN, O'Gara PT, Madias C, Pauker SG. Valvular and structural heart disease: American College of Chest Physicians Evidence-Based Clinical Practice Guidelines ( $8^{\text {th }}$ edition). Chest, 2008, 133(6 Suppl):593S-629S. https://doi.org/10.13 78/chest.08-0724 PMID: 18574274

[35] Cozma D, Streian CG, Vacarescu C, Mornos C. Back to sinus rhythm from atrial flutter or fibrillation: dabigatran is safe without transoesophageal control. Kardiol Pol, 2016, 74(5):425430. https://doi.org/10.5603/KP.a2015.0209 PMID: 26502941

[36] Ngaage DL, Mullany CJ, Daly RC, Dearani JA, Edwards WD, Tazelaar HD, McGregor CG, Orszulak TA, Puga FJ, Schaff HV, Sundt TM 3rd, Zehr KJ. Surgical treatment of cardiac papillary fibroelastoma: a single center experience with eighty-eight patients. Ann Thorac Surg, 2005, 80(5):1712-1718. https:// doi.org/10.1016/j.athoracsur.2005.04.030 PMID: 16242444

\section{Corresponding author}

Ana Lascu, MD, PhD, Discipline of Pathophysiology, Department of Functional Sciences, Victor Babeş University of Medicine and Pharmacy, 2 Eftimie Murgu Square, 300041 Timişoara, Romania; Phone +40745-803 821, e-mail: analascu@yahoo.com 